\title{
Choroidal Metastasis of Breast Cancer: A Case Report and Literature Review
}

\author{
Soumia Berrad*, Karima Oualla,Lamyae Nouiakh, Hayat Erraichi, Lamiae Amaadour, Zineb \\ Benbrahim, Samia Arifi and Nawfel Mellas
}

Department of oncology, Hassan II university hospital, Morocco

*Corresponding author: soumia berrad, Department of oncology hassan II university hospital, Fes Morocco.

To Cite This Article: soumia berrad, karima oualla, Hayat Erraichi, Oumaima syouri, Lamiae amaadour, Choroidal Metastasis of Breast Cancer: A Case Report and Literature Review. 2020 - 11(1). AJBSR.MS.ID.001617. DOI: 10.34297/AJBSR.2020.11.001617.

Received: 眥 November 11, 2020; Published: 眥 December 14, 2020

\begin{abstract}
Summary
Choroid is a very rare site of metastases but the most primary cancers leading to choroidal metastases are breast cancer then lung cancer. Generally, choroidal metastases occur late the course of cancer in the presence previously of other metastatic sites, and they were associated with poor prognosis. We report the case of a patient followed in Medical Oncology Department of Fes, for breast cancer who presented visual disorders leading to the diagnosis of choroidal metastasis. The aim of this work is to report the rarity of this metastatic site, describe the clinical, and radiological features in addition to therapeutic and prognostic aspects.
\end{abstract}

Keywords: Choroid metastasis; Breast cancer; Chemotherapy; Radiotherapy; Prognosis.

\section{Introduction}

Breast cancer can metastasize on many sites, but the choroid is an uncommon site [1]. The longer survival of patients with metastatic disease as well as advances in diagnostic tools may explain the increasing frequency of ocular involvement [2]. Choroid metastases are of the order of 2 to $7 \%$ at the metastatic stage and are often part of generalized malignancy [3]. They are a poor functional and vital prognosis, the search for the primitive must be done as quickly as possible in order to allow a specific therapeutic treatment [4]. The visual prognosis in short term is generally favorable after an individualized therapeutic approach in each case that may include chemotherapy, hormone therapy, external radiotherapy and plate radiotherapy.

\section{Case presentation}

We report the case of a 46 years old woman, treated since 1995 left breast cancer, managed by surgery, chemotherapy, radiotherapy and endocrine therapy. In 2013 she presented a controlateral breast cancer treated initially by surgery and pathology revealed an invasive ductal carcinoma, classified pT2N1M0 luminal B, her2 positive. Then she received adjuvant chemotherapy and radiotherapy then endocrine therapy with tamoxifen for 5 years. The patient pointed out the recent notion of more pronounced bilateral visual blur on the right side. The work up found lung and bone metastases. The ophthalmoscopic examination found on the right side a reduced visual acuity at $1 / 10$.

The fundus examination showed the presence of a whitish upper temporal formation, raised, with serous retinal detachment and associated with subretinal exudates and deep retinal hemorrhages, Retinal fluorescein angiography showed a retinal serous detachment opposite the superior temporal arch, with heterogeneous filling, surrounded by deep retinal hemorrhages, and indocyanine green retinal angiography had shown an area upper temporal hypofluorescent surrounded by a ring. (Figures $1-3)$.

Patient underwent a CT-guided biopsy of the pulmonary nodule was performed and the histological examination revealed a metastasis of an adenocarcinoma with the immunohistochemistry evoking the gynecological origin. The patient received a firstline chemotherapy based on docetaxel and bone, and the 
ophthalmological examination found a regression of the retinal hemorrhages, serous retinal detachment. The patient received ocular radiotherapy and she is under letrozole maintenance with disease control after a follow up of 18 months.

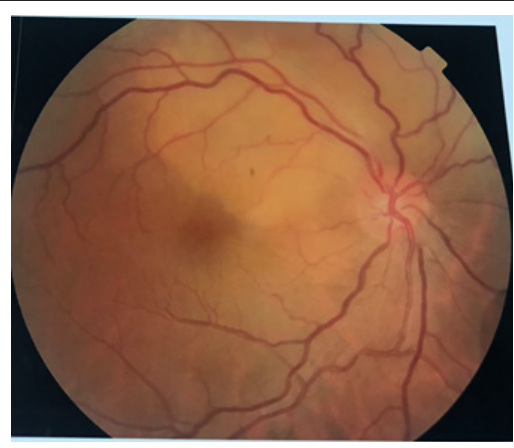

Figure 1: Image of the fundus of the right eye showing the sub-retinal mass taking the upper part of the retina, yellowish, slightly protruding and deep.
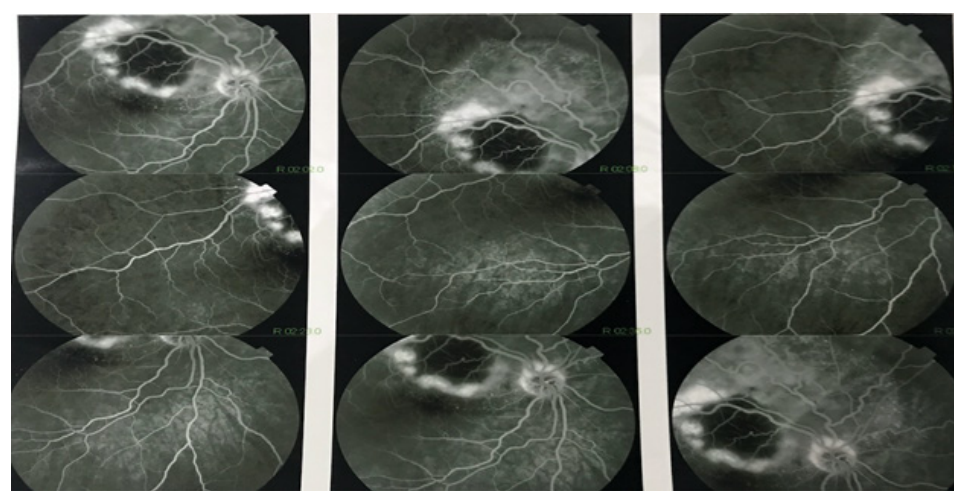

Figure 2: Fluorescein angiography of the right eye showing the heterogeneity of the impregnation of the lesion under retinal and towards retinal edema.
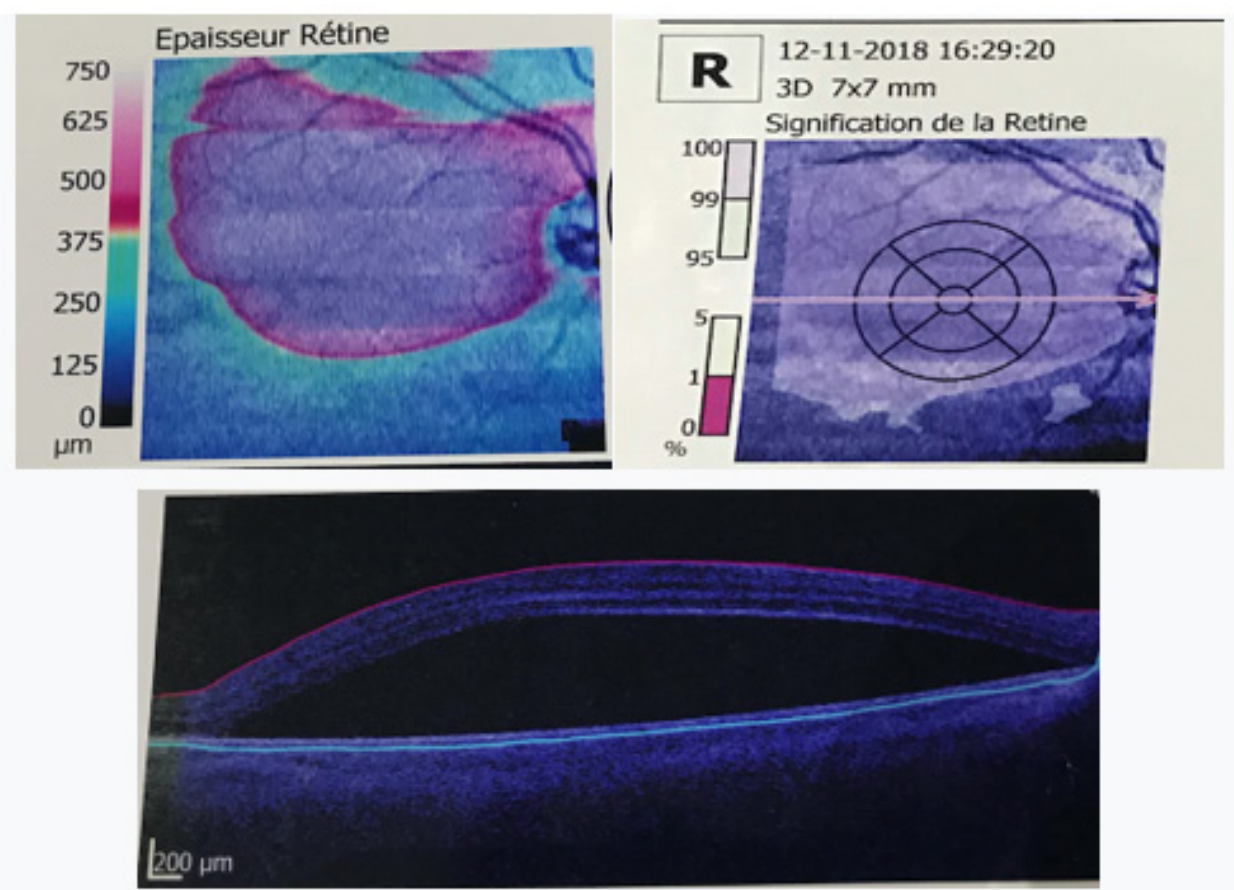

Figure 3: OCT section showing the bulging of the choroid by the tumor mass and serous retinal detachment at the right eye. 


\section{Discussion}

Breast carcinoma is the most common primary source of choroidal metastasis and it has been associated with poor prognosis. Choroidal metastases may be secondary to neoplastic infiltration or compression of orbital or ocular tissues by a metastatic tumor [5], this is due to its vascular richness and its high oxygen concentration [6]. Breast cancer and lung cancer together representing between $71 \%$ and $92 \%$ of cases. The clinical symptomatology is nonspecific and variable, choroidal metastases can be manifested by blurred vision, reduced visual acuity or floats [7].

At the back of the eye the characteristic appearance is that of an achrome placoid or domed tumor associated with a retinal detachment and whose the epicenter is usually posterior to the equator [8]. The presence of a multiple and a bilateral tumor are frequently found in metastases of breast carcinoma. Fluoroangiography is a thorough examination to examine the condition of the blood vessels in the back of the eye and mainly of the retina therefore it is the reference examination which makes it possible to specify the nature of the tumor lesion, however its interpretation remains delicate because the metastatic tumors often producing angiographic tables close to those observed in case of achromous melanoma of the choroid [8]. Fluoroangiography is a minute examination to examine the condition of the blood vessels in the back of the eye and mainly of the retina therefore it is the reference examination which makes it possible to specify the nature of the tumor lesion, however its interpretation remains delicate because metastatic tumors often producing angiographic tables close to those observed in case of achromous melanoma of the choroid [8].

Infracyanin green angiography is more useful for the relatively specific angiographic characteristics of choroidal metastasis diffuse hypofluorescence in early times, late hyperfluorescence compared to achromic melanoma or choroidal hemangioma [9]. The place of MRI in the differential diagnosis between a metastasis and a melanoma of the choroid is very reduced [10].

The treatment of choroidal metastases must be adapted according to the general condition of the patient, the stage of the disease and the severity of the visual symptoms. Its objective is to improve the patient's quality of life and maintain visual function [11]. Local treatment regimens include EBT, plate radiotherapy and complete enucleation for pain patients with very significant loss of visual focus $[12,13]$. In a retrospective study by demiciri and his colleagues External beam radiotherapy was used in 137 patients with uveal metastases (52\%), providing tumor control in 116 patients (85\%) with an average follow-up of 21 months [11].

EBRT delivered at a dose of 40 Gy on 20 fractions have been effective in improving and maintaining vision in patients with choroid metastases $[7,14]$. Plate radiotherapy is focal radiotherapy over a relatively short period of approximately 3 days. Plate radiotherapy allows satisfactory control of tumors, even in patient's resistant to other treatments [15]. The side effects of radiotherapy on plaque are comparable to those of external beam radiation therapy [16]. In case of generalized metastases, systemic chemotherapy alone or in combination with local therapy is an accepted treatment option. In choroidal patients metastases alone, local therapy has been shown to be effective, maintaining visual functions without the systemic side effects of chemotherapy [8]. The median survival rate of patients after the diagnosis of choroidal metastases is usually less than six months [17].

\section{Conclusion}

Choroidal metastases are symptomatic in $93 \%$ of cases and often occurs in the advanced stages of disseminated disease and are considered as a poor prognostic sign. Systemic chemotherapy helps control tumors in some cases, while focal therapy is recommended in tumors that cause visual loss or do not respond to systemic treatment.

\section{References}

1. De Potter P, Disneur D, Levecq L, Snyers B (2002) Manifestations occulaires des cancers. J Fr Ophtalmol 25(2): 194-202.

2. Gowri L Kanthan, Jay Jayamohan, Desmond Yip, R Max Conway (2007) Management of Metastatic Carcinoma of the Uveal Tract: an evidencebased analysis. Clin Exp Opthalmol 35(6): 553-565.

3. Gharbi Olfa, Hamdi Riadh, Tebra Sameh, Ben Hadj Hamida Fafani, Ben Ahmed Slim (2009) Breast cancer discovered from choroidal metastasis: Apropos of a case and review of the literature. Can J Ophthalmo 44(6): e67.

4. Shields CL, Shields JA, Gross NE, Schwartz GP, Sara E Lally (1997) Survey of 520 Eyes with uveal metastases. Ophthalmology 104: 1265-1276.

5. De Potter P (1998) Ocular manifestations of cancer. Curr Opin Ophthalmol 9(6): 100-104.

6. Rudoler SB, Corn BW, Shields CL, De Potter P, Hyslop T, et al. (1997) External beam irradiation for choroid metastases: identification of factors predisposing to long-term sequelae. Int J Radiat Oncol Biol Phys 38(2): 251-256.

7. Ferry AP, Font RL (1974) Carcinoma metastatic to the eye and orbit. I. A clinicopathologic study of 227 cases. Arch Ophthalmol 92(4): 276-286.

8. Shields JA, Shields CL (1992) Metastatic tumors to the intraocular structures. In: Shields JA, et al. (Eds.), Intraocular Tumors, USA, pp. $207-$ 238.

9. Shields CL (1997) Clinical evaluation of choroidal tumors. Indocyanine Green Angiography In: Yannuzzi LA, et al. (Eds.), Indocyanine Green Angiography, 279-295.

10. De Potter P, Flanders AE, Shields JA, Shields CL, Gonzales CF, Rao VM (1994) The role of fat suppression technique and gadolinium dimeglumine in the MRI evaluation of intraocular tumors and simulating lesions. Arch Ophthalmol 112: 340-348.

11. Hakan Demirci, Carol L Shields, An-Ning Chao, Jerry A Shields (2003) AOÛT 2003 Métastases uvéales dues au cancer du sein chez 264 patientes. 136(2): 264-271. 
12. Albert DM, Rubenstein RA, Scheie HG (1967) Tumor metastasis to the eye. I. Incidence in 213 adult patients with generalized malignancy. Am J Ophthalmol 63(4): 723-726.

13. Bloch RS, Gartner S (1971) The incidence of ocular metastatic carcinoma Arch Ophthalmol 85(6): 673-675.

14. Nelson CC, Hertzberg BS, Klintworth GK (1983) A histopathologic study of 716 unselected eyes in patients with cancer at the time of death. Am J Ophthalmol 95(6): 788-793.
15. Shields CL, Shields JA, De Potter P, Quaranta M, Freire J, et al. (1997) Plaque radiotherapy for the management of uveal metastasis. Arch Ophthalmol 115(2): 203-209.

16. Lim J, Petrovich Z (2000) Radioactive plaque therapy for metastatic choroidal carcinoma. Ophthalmology 107(10): 1927-1931.

17. Pugnet G, Arista S, Martin-Blondel G, Roche H (2007) Métastase choroïdienne révelant un cancer du sein. La revue de médecine interne 28(11): 790-792. 